\title{
Simulating the Daily Evolution of West African Monsoon Using High Resolution Regional Cosmo-model: A Case Study of the First Half of 2015 over Nigeria
}

\author{
Eniola Olaniyan ${ }^{1 *}$, Ernest Afiesimama1 ${ }^{1}$, Feyi Oni² and Kamoru A. Lawal ${ }^{1}$ \\ ${ }^{1}$ National Weather Forecasting and Climate Research Centre, Nigerian Meteorological Agency, Abuja, Nigeria \\ ${ }^{2}$ Department of Geography, University of Lagos, Lagos, Nigeria
}

\begin{abstract}
Understanding the dynamics and variability of the West African Monsoon (WAM) at daily time scales will improve skillful prediction of the onset and evolution of the monsoon and thus would contribute toward food security of Nigeria. This study, therefore, uses high resolution regional COSMO-model, a weather-mode model from the German Weather Service adopted by the Nigerian Meteorological Agency, to study the daily evolution of WAM as well as the ability of the model to predict the daily characteristics of monsoon, for the first half of 2015, over Nigeria. Results show that, qualitatively, the model has the ability to predict the daily evolution of WAM, daily variability of rainfall, which includes the onset of the raining season as well as dry-spells, over Nigeria. The spatial correlations between the observation and the forecast are generally greater than 0.64 , implying that the model, though, underestimates the rainfall amount as much as half of the actual amount, it nevertheless proved to have a good representation of the spatial characteristics of the rain over Nigeria. The model shows that the Inter-Tropical Discontinuity (ITD) advances northward, from the Gulf of Guinea (GOG) to the Sahelian region, by about $0.42^{\circ}$ per week; and that for the onset of monsoon in Nigeria, the average position of the ITD should be at least $6.7^{\circ} \mathrm{N}$ and must not retreat south of it in the subsequent average weekly position. In agreement with earlier findings, the model also shows that the African Easterly Jet (AEJ), together with its associated core, is not only a boreal summer element but can also exist during the boreal winter with the same strength in the wind speed. The atmospheric thermodynamic properties, predicted by the model, show that for an onset of the rains, a threshold value of at least $1500 \mathrm{~J} / \mathrm{Kg}$ of convective available potential energy (CAPE) may be required. The results suggest that COSMO-Model has proved to be a good tool for operational daily weather forecast; therefore, the model could also have potential for seasonal rainfall predictions over Nigeria when run in climate mode.
\end{abstract}

\section{Keyword: CAPE; COSMO-model; Monsoon onset; Nigeria}

Abbrevations: ITD: Inter-Tropical Discontinuity; ICTP: International Centre for Theoretical Physics; AEJ: African Easterly Jet

\section{Introduction}

All socio-economic activities in Nigeria are inter-twined with the monsoon. [1,2] and [3] described monsoon as a system that is characterized by major intense rainfall events in the Gulf of Guinea (GOG) from mid boreal spring, through boreal summer, and a retreat back to the south in early boreal autumn providing evidence of the seasonal migration of the Inter-Tropical Discontinuity (ITD). On the other hand, [4] describe monsoon systems as that coupled atmosphereocean-land phenomena that are primarily driven by seasonal and latitudinal differences in incoming solar radiation [5]. visualize that the different heat capacities of oceans and continents lead to considerably strong thermal differences thereby forming large-scale atmospheric circulations popularly referred to as the monsoon; and that the largescale circulation reverses seasonally and is, as usual, accompanied by summer rainfall. Over Nigeria, the common consensus is that during the monsoon season the country receives moisture from the tropical Atlantic via low-level southwesterly flow across her southern coast. At the surface, this moist southwesterly airstream can penetrate beyond the country as far as the southern fringes of the Sahara Desert near $20^{\circ} \mathrm{N}$ see Figure 1. The country's socio-economic activities, which include agriculture and water management, rely heavily on rainfall during the monsoon. An ordinarily moderate decrease in monsoon rainfall or shift in the north-south extent of the monsoon can have significant socio-economic impacts on the country, as over $75 \%$ of Nigerians are peasant farmers. These farmers are only interested in the onset of the monsoon to ascertain that the rains will become fairly continuous and sufficient to ensure enough moisture in the soil at the time of planting and that it will be maintained or even increase as the rainy season advances [6-8]. The monsoon affects the people's livelihood to grow foods to feed themselves. In addition, the monsoon provides most of the rainfall over the Sahel zones of the country [9] thereby contributing immensely to the crucial water supply of the zones. Monsoon, which returns with remarkable regularity each summer, is therefore the main driver for health, food security and the economy of Nigeria. Therefore, understanding the dynamics and variability of the monsoon at daily time scales is important for the people of Nigeria. The understanding will also improve our skill in predicting the onset and evolution of the monsoon and thus would contribute toward food security of the country. In this paper, we focus on the daily performance of the high resolution regional COSMO-model simulations and how it is able to capture the evolution of the West African Monsoon (WAM) over Nigeria. (Figure 1).

*Corresponding author: Eniola Olaniyan, National Weather Forecasting and Climate Research Centre, Nigerian Meteorological Agency, Abuja, Nigeria. Tel: +234-9-413-0709; E-mail: olaniyan.eniola67@gmail.com

Received September 03, 2015; Accepted November 09, 2015; Published November 15, 2015

Citation: Olaniyan E, Afiesimama E, Oni F, Lawal KA (2015) Simulating the Daily Evolution of West African Monsoon Using High Resolution Regional Cosmo-model: A Case Study of the First Half of 2015 over Nigeria. J Climatol Weather Forecasting 3: 142. doi:10.4172/2332-2594.1000142

Copyright: (c) 2015 Olaniyan E, et al. This is an open-access article distributed under the terms of the Creative Commons Attribution License, which permits unrestricted use, distribution, and reproduction in any medium, provided the original author and source are credited. 


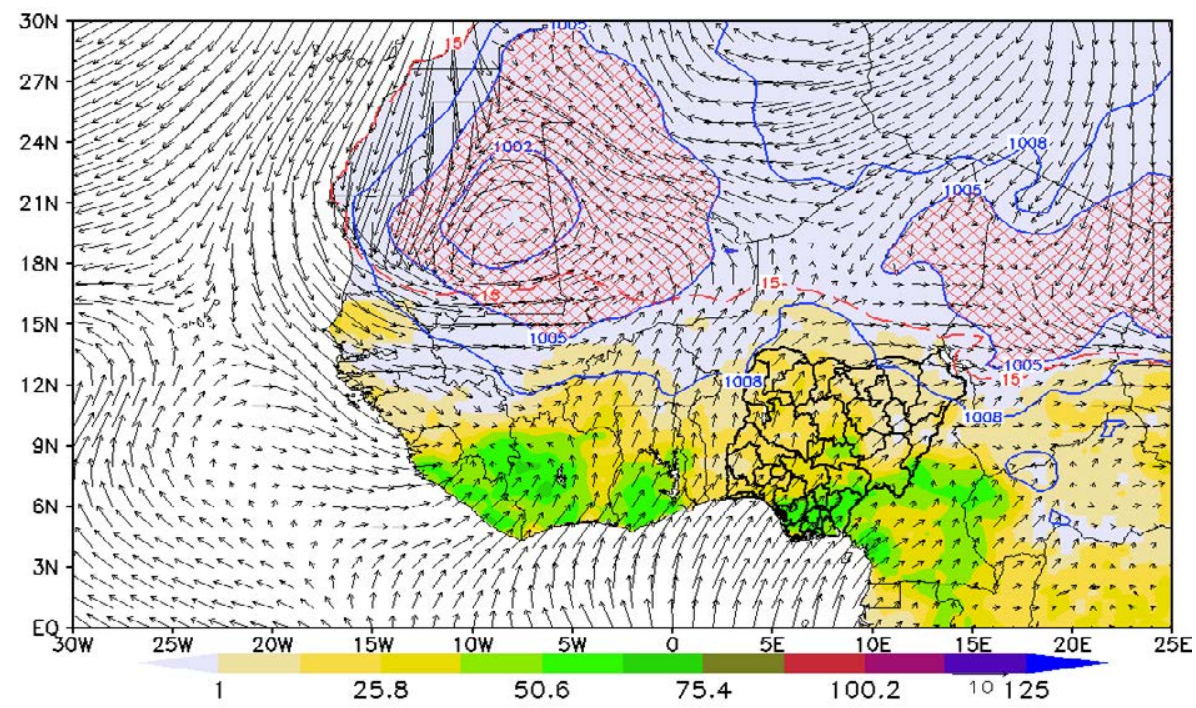

Figure 1: Mean atmospheric structure of the monsoon over the West African sub-region during the boreal summer season. The red dash line is the 15oC Isodrosotherm (a line connecting points of equal dew point temperature), the red hatched area is the thermal heat low, while the shaded is the spatial distribution of rainfall from ECMWF ERA-INTERIM reanalysis dataset.

Several climate models, global or regional, have been used to study the seasonal, as well as inter-annual, characteristics of the West African monsoon. For instance, [10] examines and evaluates the mean state and the inter-annual variability of the West African monsoon as simulated by the International Centre for Theoretical Physics (ICTP) Regional Climate Model version 3 (RegCM3) using the National Center for Environmental Prediction (NCEP) National Center for Atmospheric Research (NCAR) reanalysis data as lateral boundary conditions. They found that the averaged rainfall over the West African region is well represented by the model and that the model demonstrates considerable skill in reproducing the extreme rainfall regimes [11]. Have shown the capability of a non-hydrostatic global climate model with grid stretching that uses NCAR Community Atmospheric Model (CAM) physics and EULAG dynamics to simulate African easterly jet and monsoon circulations over West Africa in summer. In the same manner, [9] investigates the synoptic variability of the monsoon flux during the establishment of the West African monsoon using observations and ECMWF analyses. They are able to identify the heat-low dynamics, which is predominantly continental in nature, as a major driver of the synoptic penetrations of the monsoon. Using the COSMO-model simulations in climate mode (COSMO-CLM), [12] evaluates three present-day simulations over Africa in order to quantify the ability of the model to reproduce the main monsoon features. They showed that, even with state-of-the-art climate models, the simulation of complex atmospheric system such as the WAM is still subject to errors. They nevertheless concluded that COSMO-CLM proved to be a useful tool to investigate the monsoon system. These studies and other unmentioned studies give useful insight into the capabilities of climate models to simulate and or capture the seasonal and inter-annual characteristics of the West African monsoon. They however do not give any information on the daily evolution of the monsoon and the ability of a weather model to simulate and or capture its daily characteristics. This study will address this concept using the high resolution regional COSMO-model-a weather-mode model adopted by the Nigerian Meteorological Agency (NiMet) to make daily weather prediction. Though, the model has been operationally active since 2010 [13], however, it is still very pertinent to know how well the model could be relied upon in the forecasting of the daily evolution of the monsoon structures over the country.

This paper is arranged as follows: the next section describes the model the configuration and datasets. Section 3 describes the results from our analyses while section 4 summarizes and concludes the findings of the paper.

\section{Model Configuration and Datasets}

The COSMO-Model is a non-hydrostatic limited-area atmospheric prediction model. It has been designed for both operational numerical weather prediction (NWP) and various scientific applications. The COSMO-Model is based on the primitive thermo-hydro-dynamical equations describing compressible flow in a moist atmosphere. The model equations are formulated in rotated geographical coordinates and a generalized terrain following height coordinate. The main physical parameterization schemes, which take into account a variety of physical processes [14], include: the radiative transfer scheme by [15], the Tiedtke parameterization of convection [16] being modified by D. Mironow a turbulence scheme [17] based on prognostic turbulent kinetic energy closure at level 2.5 according to [18].

The explicit simulation of deep convection poses a special challenge for the microphysical parameterization. Here, the cloud microphysics of convective storms is much more complicated than in stratiform clouds, therefore the microphysics scheme of the COSMO model has been extended to include riming processes (graupel formation): i.e. the new scheme is formulated as a Lin-type one-moment cloud microphysics scheme that predicts cloud water, rainwater, cloud ice, snow, and graupel $[19,20]$. The model is run on a regular grid domain of $2^{\circ}-15^{\circ} \mathrm{E}$ Longitude and $3^{\circ}-15^{\circ} \mathrm{N}$ Latitude covering Nigeria and some neighboring countries like Benin, Niger, Chad, Central African Republic, and Cameroun. We adopt a horizontal grid spacing of $7 \mathrm{~km}$ which leads to $209 \times 193$ grid boxes as shown in Figure 2. COSMOModel, in weather mode over the domain, is forced from the 3-hourly initial and boundary dataset derived from an interpolation analysis of $13 \mathrm{~km}$ Icosyhedral Non-hydrostatic Global Model (ICON) from the DWD [14]. The model is simulated for 48 hours at 3-hour time-steps. 
Citation: Olaniyan E, Afiesimama E, Oni F, Lawal KA (2015) Simulating the Daily Evolution of West African Monsoon Using High Resolution Regional Cosmo-model: A Case Study of the First Half of 2015 over Nigeria. J Climatol Weather Forecasting 3: 142. doi:10.4172/2332-2594.1000142

Page 3 of 8

This makes 17 outputs everyday (00hour of the third day inclusive) with emphasis on the first forecast day. However, forecast for precipitation spills into the 06hour of the second forecast day (Figure 2).

Figure 3 shows the geographical location of some Nigerian meteorological stations considered in this study. Observed daily data used in this study, obtained from NiMet archive, consist of maximum temperature and $24 \mathrm{hr}$ rainfall accumulation from more than 42 meteorological stations. Though, the station datasets, which represent the conditions at the measuring location, are not regularly gridded but the stations are chosen such that they are representative of the surrounding area. Here, the simulation results are defined at the center of an Arakawa-C grid box [21]. The daily datasets start from January to June 2015 and some meteorological parameters from the forecast results were extracted and concatenated for this period as well. These meteorological parameters from the forecast results, of the first forecast day, include:

- Dew point temperature at $2 \mathrm{~m}$ taken at $15 \mathrm{hr}$ (being generally the driest hour of the day).

- The highest daily convective available potential energy (CAPE).

- The maximum temperature at $2 \mathrm{~m}$.

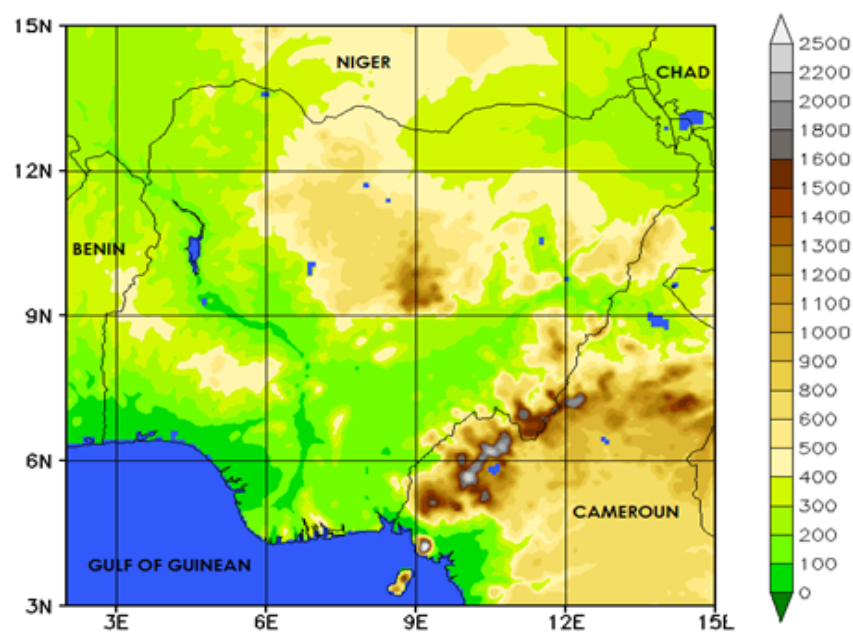

Figure 2: Topography of the domain covered by the COSMO-Model.
- The strongest daily easterly winds at $700,650,600$ and $500 \mathrm{hPa}$ level, and

- The $24 \mathrm{hr}$ accumulation of rainfall from 0601hour of the first forecast day to the 06hour of the second forecast form the total precipitation (TOTPREC) for the first forecast day.

Performance evaluation of the model is based on the comparison between observational datasets and the simulation results [22] (Figure 3).

\section{Results}

Position of the ITD is of crucial importance in understanding the evolution of WAM. Though called different names by different authors, this paper identifies ITD with the $15^{\circ} \mathrm{C}$ Isodrosotherm (i.e., a line connecting points of equal dew point temperature; Figure 1) in consistency with [23]. Figure 4 depicts a latitude-time daily evolution of ITD and rainfall accumulation, from the COSMO-Model, computed at $2^{\circ}-15^{\circ} \mathrm{E}$ longitudinal average. The figure shows that the model has the ability to simulate and or duplicate the complex daily variability of rainfall accumulation and the annual migration of the ITD from GOG

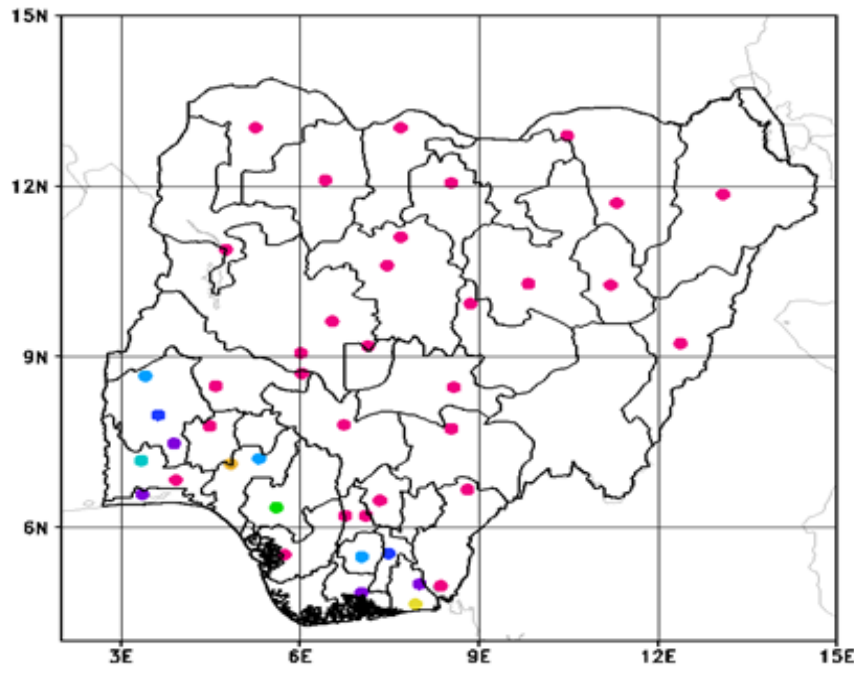

Figure 3: Geographical location of some synoptic meteorological stations used maintained by the Nigerian Meteorological Agency (NiMet).

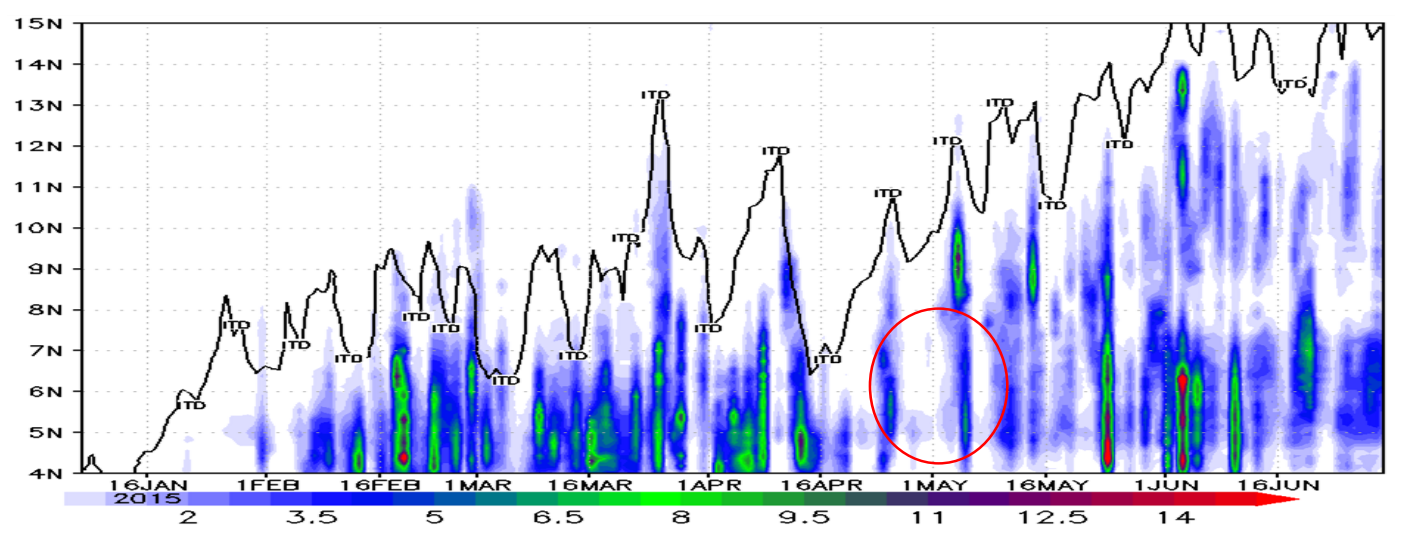

Figure 4: Latitude-time daily evolution of ITD (black line) and rainfall accumulation (shaded) as forecast by the COSMO-Model computed at $20-15^{\circ} \mathrm{E}$ longitudinal average. Red circle indicates the period of dry spells forecast over Nigeria. 


\begin{tabular}{|c|c|c|c|}
\hline Station & Longitude & Latitude & Onset Date \\
\hline Benin & 5.60 & 6.33 & 75(March) \\
\hline Calabar & 8.35 & 4.97 & 68(March) \\
\hline Eket & 7.92 & 4.63 & 69(March) \\
\hline Enugu & 7.00 & 6.50 & 99(April) \\
\hline Ikeja & 3.33 & 6.58 & 78(March) \\
\hline Ilorin & 4.58 & 8.48 & 100(April) \\
\hline Kano & 8.53 & 12.05 & 154(June) \\
\hline Lokoja & 6.73 & 7.80 & 110(April) \\
\hline Maiduguri & 13.08 & 11.85 & 168(june) \\
\hline Port Harcourt & 7.12 & 4.85 & 63(March) \\
\hline Sokoto & 5.20 & 12.92 & 152(June) \\
\hline
\end{tabular}

Table 1: Climatology of rainfall onset dates (in Julian days) for some selected stations used in this study. Source: (NiMet SRP).

to the Sahelian region. Here, the ITD is observed to advance northward by about $0.42^{\circ}$ per week.

The model has the capability to forecast the onset of rainfall over Nigeria. Visual comparison of Figure 4 to Table 1 shows that COSMO-Model, to some extent, reproduces the climatological onset dates of the rainy season over some selected meteorological stations. Furthermore, another comparison of Figures 4 and 5 (panels a-e) shows that the model is also capable of replicating dry spells over the country. For instance, the period of dry spells observed over some selected meteorological stations, as depicted in Figure 5 (panels a-e), coincides with the periods of dry spells forecast by the COSMO-Model (Figure 4). The complex weekly variability in the position of ITD also lends credence to the occurrence of the dry spells. Figure $5 \mathrm{f}$ shows that there is an unusual oscillation in the north-south movement of the ITD. The figure indicates that ITD, as indicated by the $14-16^{\circ} \mathrm{C}$ isodrosotherm, retreat southward in the third week of April before advancing northward, again, in the last week. This abrupt southward migration of the ITD puts these selected meteorological stations under the no rain zone usually found immediately south of the ITD [22] (Figure 4) (Table 1).

(Figure 5) Qualitatively, COSMO-Model has the ability to forecast areas of high and low rainfall values. Structural comparisons of the spatial distribution of rainfall over Nigeria as observed and forecast by the model shows that, though, the model underestimates the rainfall amount as much as half of the actual amount, it however proved to have a good representation of the spatial characteristics of the rain over Nigeria (Figure 6a-f). For instance spatial correlations between the observation and the forecast are generally greater than 0.64 .

(Figure 6) CAPE, one of the measures of instability [23], is a very important index in the forecasting of rainfall over Nigeria. Figure 7 show that the daily evolution of CAPE follows the same pattern as the complex daily variability of rainfall accumulation and the annual migration of the ITD from GOG to the Sahelian region. The figures shows the steady advancement of CAPE northward and also suggests that, before the onset of rain, a threshold value of about $1500 \mathrm{~J} / \mathrm{Kg}$ of CAPE may be required for at least 2 days at any station of reference. This implies that the contribution of CAPE in the evolution of monsoon over Nigeria is very essential. (Figure 7).

The effective contribution of the African Easterly Jet [24,25] as forecast by the COSMO-model is also investigated in this study. The strongest daily easterly winds at 700, 650, 600 and $500 \mathrm{hPa}$ levels show that the location and strength of the AEJ core may be one of the determining features for rainfall pattern over West Africa and Nigeria in particular. Figure 8 shows that the daily evolution of the AEJ core is, though, complex; it however shows the steady northward migration of the core, from January to June, at all the four levels. The figure shows that the core, in consistency with the findings of [25], is not only a boreal summer feature but can also exist during the boreal winter with the same strength in the wind velocity. The core of the jet is located over the GOG in January to February at $700 \mathrm{mb}$ level. The core temporarily exists at $650 \mathrm{mb}$ during the boreal spring (Figure 8) and reaches 600 mb level during boreal summer. Simultaneously, the core of the AEJ advances northward beyond $14^{\circ} \mathrm{N}$ during boreal summer. These imply that COSMO-Model exhibit realistic meridional structure of the AEJ. That is, the model has shown that the evolution of the monsoon onset, in 2015, may be connected to when the core of the jet exist at about $7^{\circ} \mathrm{N}$ around $650 \mathrm{mb}$ level and advances northwards without retreating southward of $7^{\circ} \mathrm{N}$. (Figure 8).

\section{Conclusion}

NiMet, in its quest to excel in the provision of daily weather prediction to stakeholders, adopted a high resolution regional COSMOmodel, a weather-mode model, to make daily weather predictions 48 hours ahead at 3hour time steps. This work uses the model to study the daily evolution of WAM and the ability of the model to predict the daily characteristics of monsoon, for the first half of 2015, over Nigeria. Since monsoon, which returns with remarkable regularity each summer, is the main driver for health, food security and the economy of Nigeria; therefore, understanding the dynamics and variability of the monsoon at daily time scales is important for the people of Nigeria. The understanding will improve our skill in predicting the onset and evolution of the monsoon and thus would contribute toward food security of the country.

Results show that the high resolution regional COSMO-model has the ability to predict the evolution of WAM over Nigeria. Qualitatively, the model predicted the daily variability of rainfall, which includes the onset of the raining season as well as dry-spells, over the country. Though the model underestimates the rainfall amount as much as half of the actual amount, it however proved to have a good representation of the spatial characteristics of the rain over Nigeria as the spatial correlations between the observation and the forecast is generally greater than 0.64 . The model also predicted, satisfactorily, the annual migration of the ITD from GOG to the Sahelian region. The model shows that ITD advances northward by about $0.42^{\circ}$ per week; and that for the onset of monsoon in Nigeria, the average position of the ITD should be at least $6.7^{\circ} \mathrm{N}$ and must not retreat south of it in the subsequent average weekly position. In addition, the model has the capability to predict the threshold of CAPE at any station of reference before the onset of rain. In agreement with earlier findings, the model also shows that AEJ, together with its associated core, is not only a 


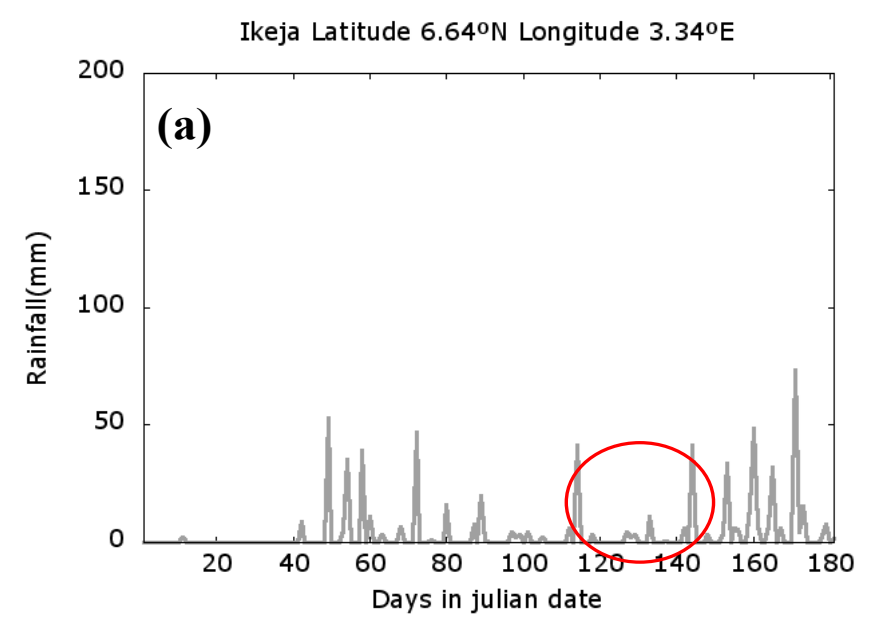

Benin Latitude $6.35^{\circ} \mathrm{N}$ Longitude $5.60^{\circ} \mathrm{E}$

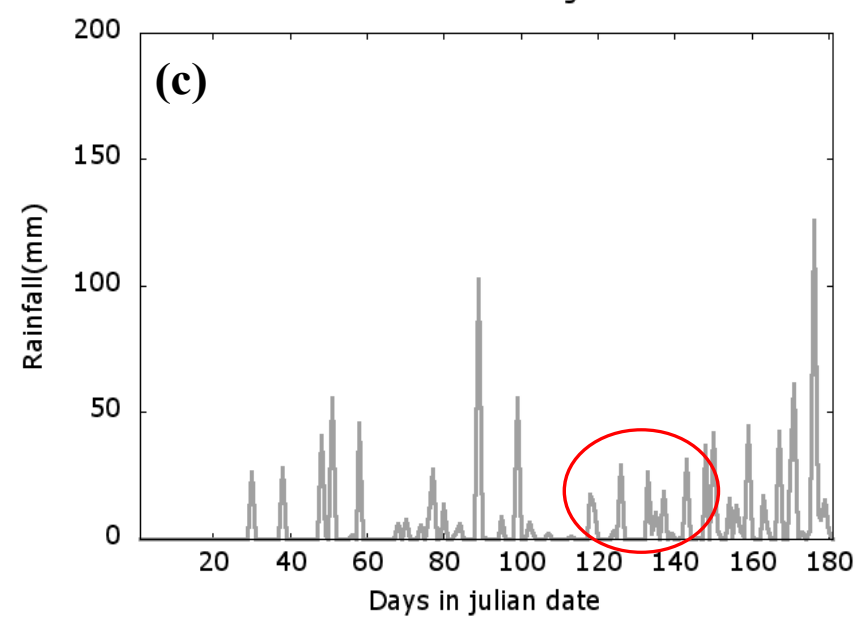

Eket Latitude $4.65^{\circ} \mathrm{N}$ Longitude $7.93^{\circ} \mathrm{E}$

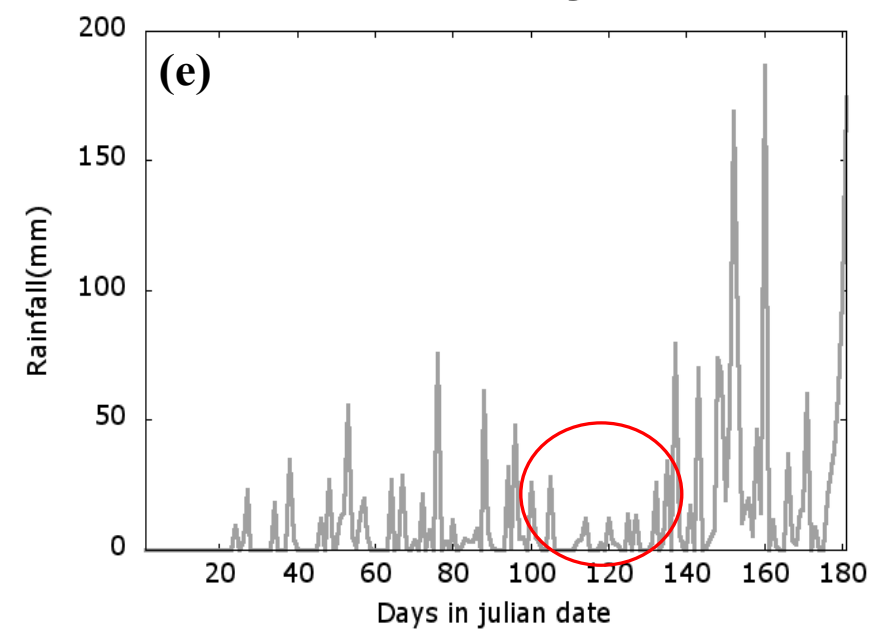

PortHarcourt Latitude $4.85^{\circ} \mathrm{N}$ Longitude $7.02^{\circ} \mathrm{E}$

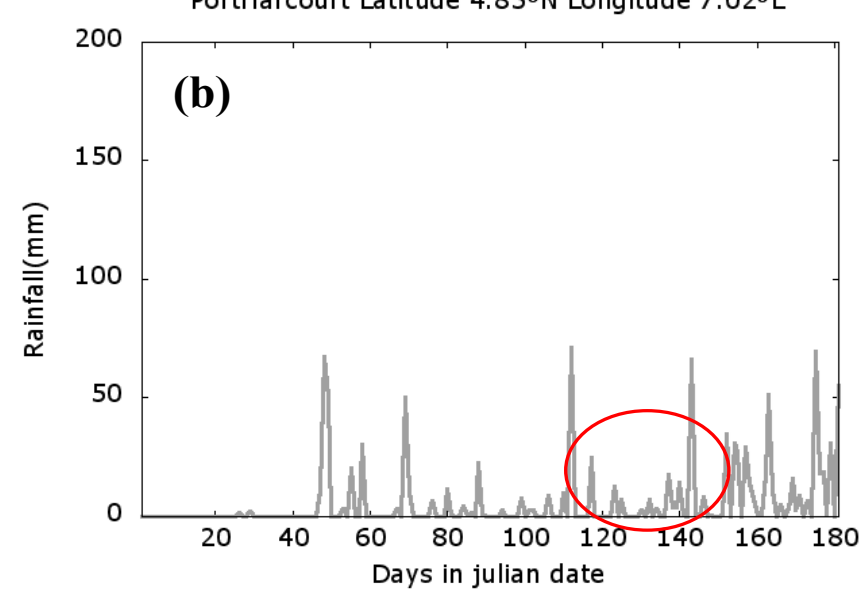

Enugu Latitude $6.47^{\circ} \mathrm{N}$ Longitude $7.33^{\circ} \mathrm{E}$
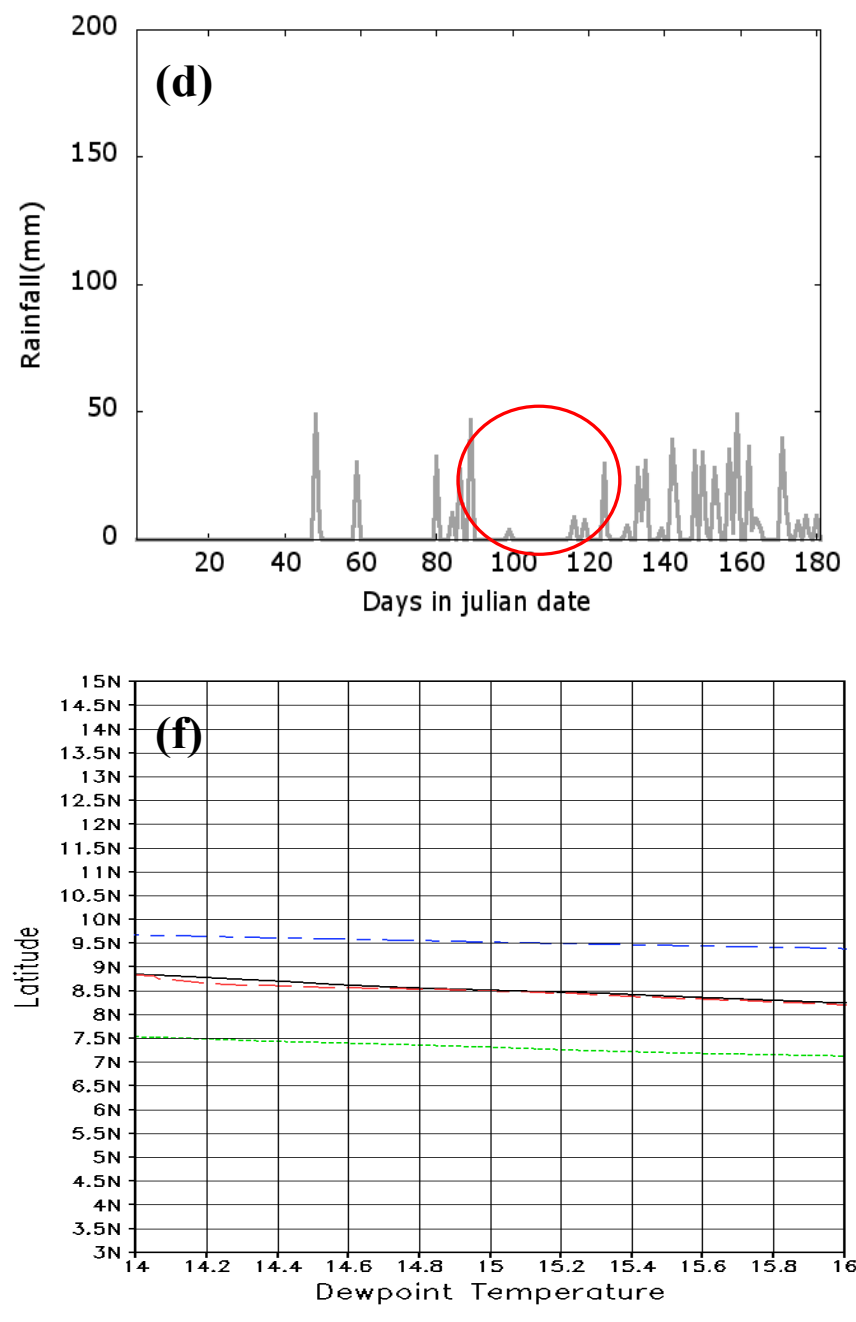

Figure 5: Time series of daily rainfall over (a) Ikeja, (b) Port-Harcourt, (c) Benin, (d) Enugu, (e) Eket and (f) the model average ITD position, as indicated by 14-16oC isodrosotherm, in the month of April (Week1 - black, Week2 - red, Week3 - green and Week4 - blue). 

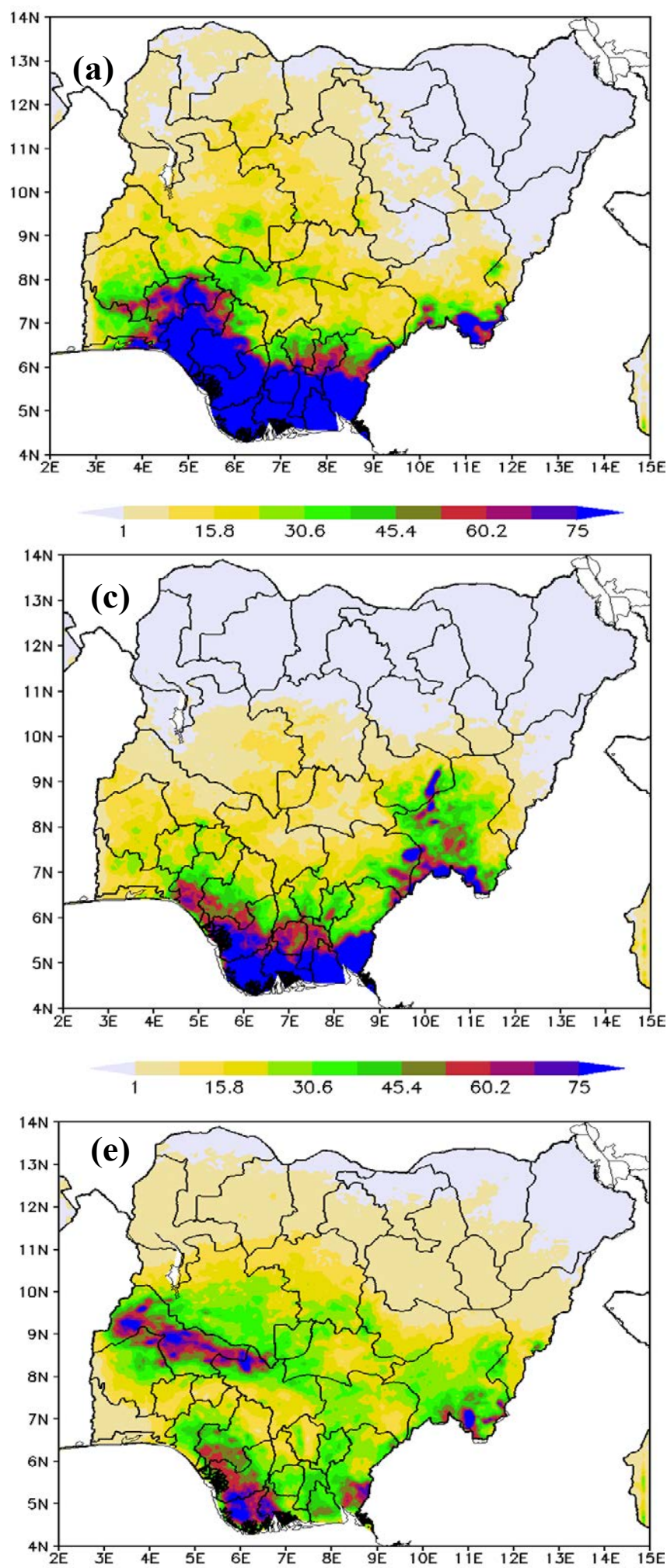

$\begin{array}{llll}30.8 & 60.6 & 90.4 & 120.2 \quad 150\end{array}$
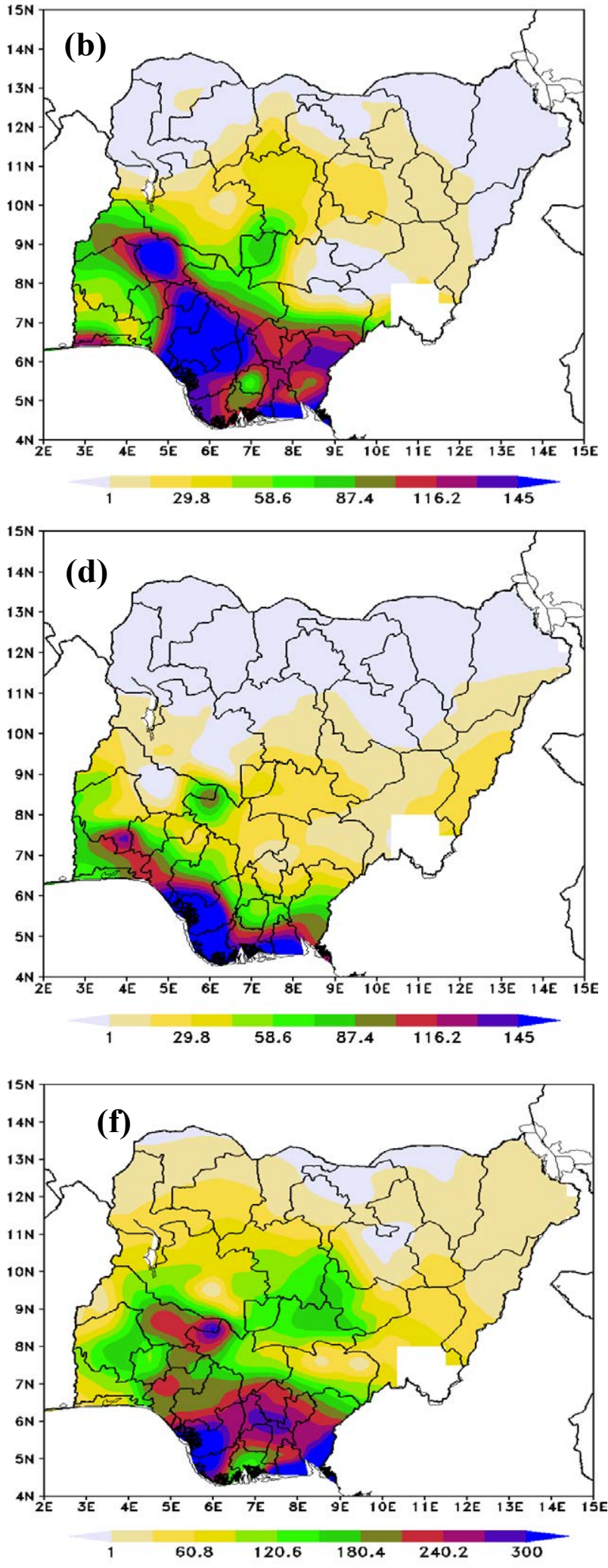

Figure 6: Spatial distribution of rainfall accumulation forecast by the COSMO-model (left column) and the observation (right column) for the months of March (top row), April (middle row) and May (bottom row) over Nigeria. 


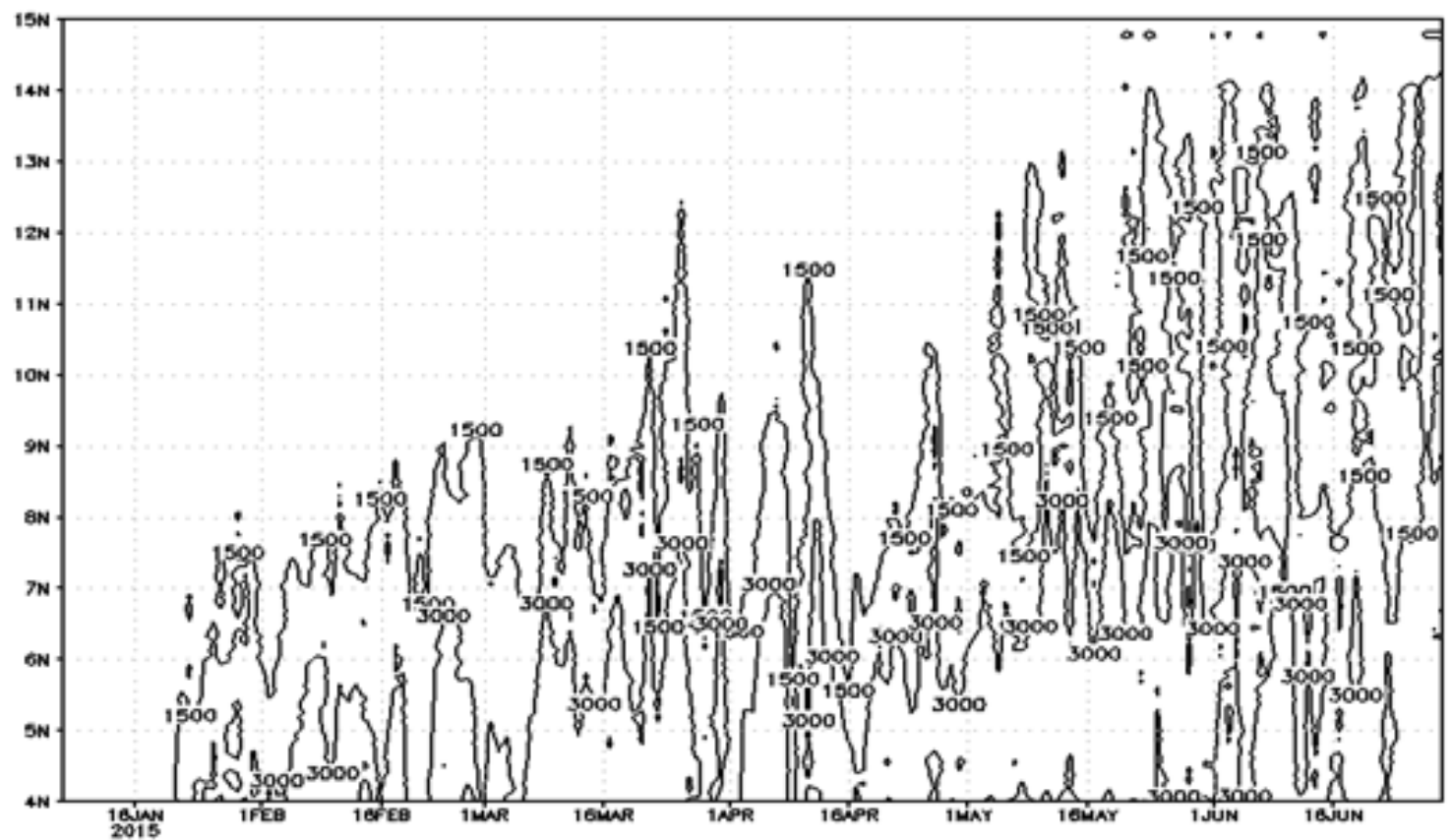

Figure 7: Latitude-time daily evolution of the convective available potential energy (CAPE) as forecast by the COSMO-Model computed at $20-15^{\circ} \mathrm{E}$ longitudinal average.
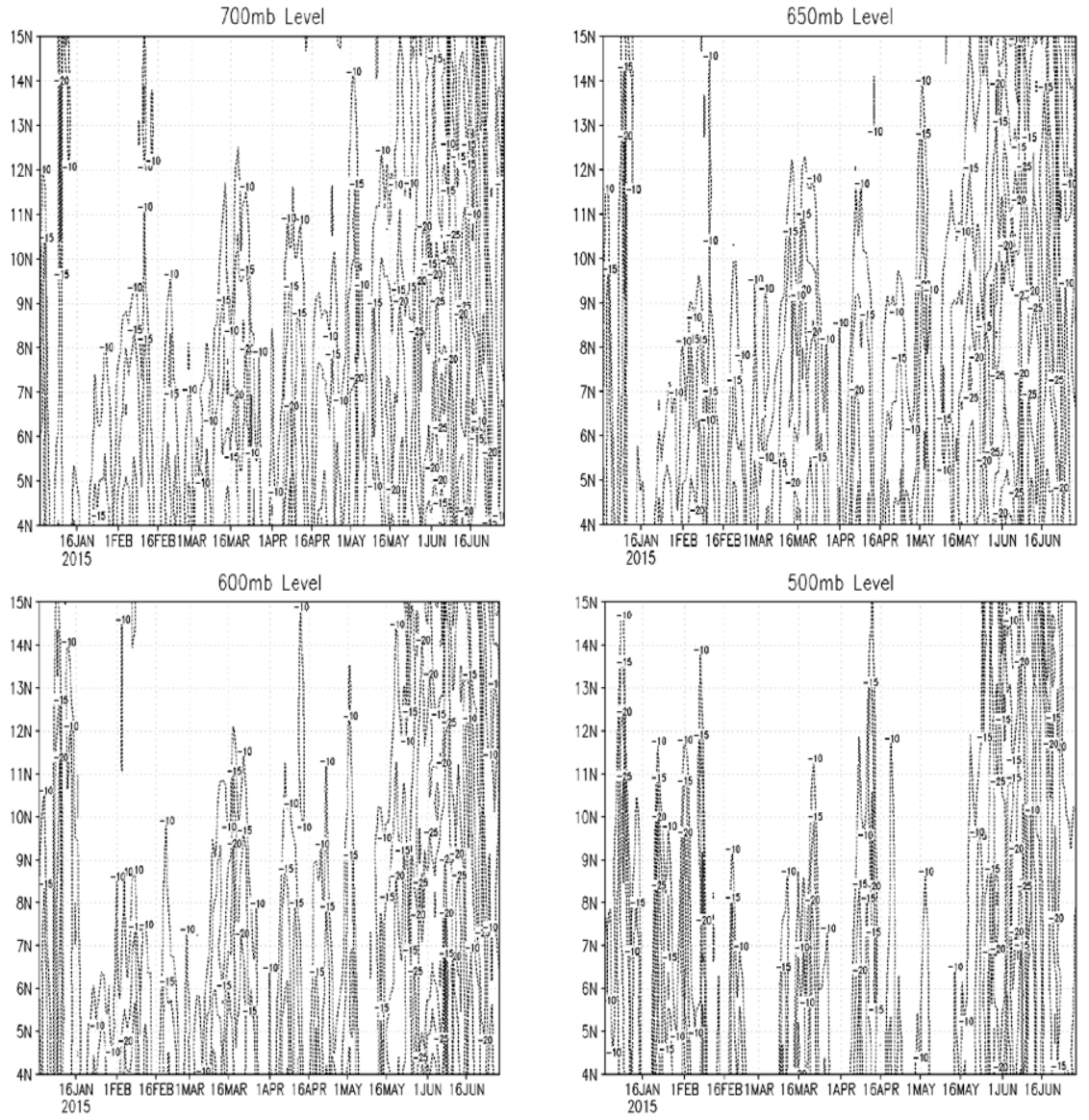

Figure 8: Latitude-time daily evolutions of the strongest daily easterly winds at 700,650, 600 and $500 \mathrm{hPa}$ levels as forecast by the COSMO-Model computed at $20-15^{\circ} \mathrm{E}$ longitudinal average. 
boreal summer feature but can also exist during the boreal winter with the same strength in the wind velocity.

Seasonal rainfall prediction through high resolution dynamical downscaling does not exist in Nigeria. Nevertheless, results from this study suggest that COSMO-Model has proved to be a good tool for operational daily weather forecast; therefore, the model could also be suitable for seasonal rainfall predictions over Nigeria when run in climate mode. The authors believe that running the COSMO-Model for just 180 days is not sufficient for proper and in-depth understanding of the WAM over Nigeria. They also agree that it is not enough to justify the operational use of a model in whatever mode. They therefore recommend that more studies, which may encompass longer years of data, be carried out to ascertain the reliability of the COSMO-Model. This will definitely aid our understanding of the daily evolution of the WAM, thereby improving our skill in predicting its onset and thus contribute positively toward food security of Nigeria.

\section{References}

1. Sultan B, Janicot S (2000) Abrupt shift of the ITCZ over West Africa and intraseasonal variability. Geophys Res Lett 27: 3353-3356.

2. Le Barbe L, Lebel T, Tapsoba $D$ (2002) Rainfall variability in West Africa during the years 1950-90. J. Climate 15: 187-202.

3. Redelsperger JL, Diongue A, Diedhiou A, Ceron JP, Diop M, et al. (2002) Multiscale description of a Sahelian synoptic weather system representative of the West African monsoon. Q. J. R. Meteorol. Soc 128: 1229-1257.

4. Dallmeyer A, Claussen M, Fischer N, Haberkorn K, Wagner S, et al. (2015) The evolution of sub-monsoon systems in the Afro-Asian monsoonregion during the Holocene-comparison of different transient climate model simulations. Clim. Past 11: 305-326.

5. Webster PJ, Magana VO, Palmer TN, Shukla J, Tomas RA, et al. (1998) Monsoons: Processes, predictability, and the prospects for prediction, J. Geophys 103: 14451-14510.

6. Anyadike RNC (1992) Regional variations in fluctuations of seasonal rainfal over Nigeria. Theoretical and Applied Climatology 45: 285-292.

7. Hess TM, Stephens W, Maryah UM (1995) Rainfall trends in the north east arid zone of Nigeria 1961-1990. Agricultural and Forest Meteorology 74: 87-97.

8. Ati FO (2002) A comparison of methods to detect the onset of the growing season and its trends for some stations in the Sudan Savanna of Northern Nigeria. International Journal of Climatology Int. J. Climatol 22: 731-742.

9. Couvreux F, Guichard F, Bock O, Campistron B, Lafore JP, et al. (2010) Synoptic variability of the monsoon flux over West Africa prior to the onset. $Q$. J. R. Meteorol. Soc 136: 159-173
10. Afiesimama EA, Pal J, Abiodun BJ, Gutowski WJ, Adedoyin A (2006) Simulation of West African Monsoon using the RegCM3. Part I: Model validation and interannual variability. International Journal of Climatology 86: 23-37.

11. Abiodun BJ, Gutowski WJ, Abatan AA, Prusa JM (2011) CAM-EULAG: A NonHydrostatic Atmospheric Climate Model with Grid Stretching. Acta Geophysica 59: 1158-1167.

12. Koth S (2013) Analysis of the West African Monsoon system in the regiona climate model COSMO-CLM. International Journal of Climatology 34: 481-493.

13. Olaniyan E, Afiesimama E (2013) Simulation Of Meso-Scale Convective Systems Using A High Resolution Model As Early Warning Tool For Flooding Over Nigeria. Proceedings of the Nig. Met. Society 146-150.

14. Ritter B, Geleyn JF (1992) A comprehensive radiation scheme for numerical weather prediction models with potential applications in climate simulations. Mon Weather Rev 120: 303-325.

15. Majewski D, Liermann D, Prohl P, Ritter B, Buchhold M (2002) The operationa global icosahedral-hexagonal gridpoint model GME: Description and highresolution tests. Monthly Weather Review 130: 319-338.

16. Tiedtke M (1989) A comprehensive mass flux scheme for cumulus parameterization in large-scale models. Monthly Weather Review 117: 17791800.

17. Mironov D, Raschendorfer M (2001) Evaluation of empirical parameters of the new LM surface-layer parameterization scheme: results from numerical experiments including soil moisture analysis. COSMO technical report 1, DWD, Offenbach, Germany.

18. Mellor GL, Yamada T (1982) Development of a turbulence closure model for geophysical fluid problems. Reviews of Geophysics 20: 851-875.

19. Lin Y, Farley RD, Orville $H$ (1983) Bulk parameterization of the snow field in a cloud model. J. Climate Appl. Meteor 22: 1065-1092.

20. Reinhardt T, Seifert A (2006) A three-category ice scheme for LMK. Cosmo News letter 6: 115-120.

21. Arakawa A, Lamb VR (1977) Computational design of the basic dynamica processes of UCLA general circulation model. Methods in Computational Physics 17: 173-265.

22. Ilesanmi Olufemi O (1971) An emperical formulation of an ITD rainfall model for the tropics: a case study of Nigeria. J.appl clim 10: 882-891.

23. Zipser EJ, LeMone MA (1980) Cumulonibus vertical velocity events in GATE. Partll: Synthesis and model core structure. J.Atmos.Sci 37: 2458-2469.

24. Cook KH (1999) Generation of the African easterly jet and its role in determining West African precipitation. J. Climate 12: 1165-1184

25. Afiesimama EA (2007) Annual cycle of the mid-tropospheric easterly jet over West Africa. Theor. Appl. Climatol 90: 103-111.
Citation: Olaniyan E, Afiesimama E, Oni F, Lawal KA (2015) Simulating the Daily Evolution of West African Monsoon Using High Resolution Regional Cosmo-model: A Case Study of the First Half of 2015 over Nigeria. J Climatol Weather Forecasting 3: 142. doi:10.4172/2332-2594.1000142

\section{OMICS International: Publication Benefits \& Features}

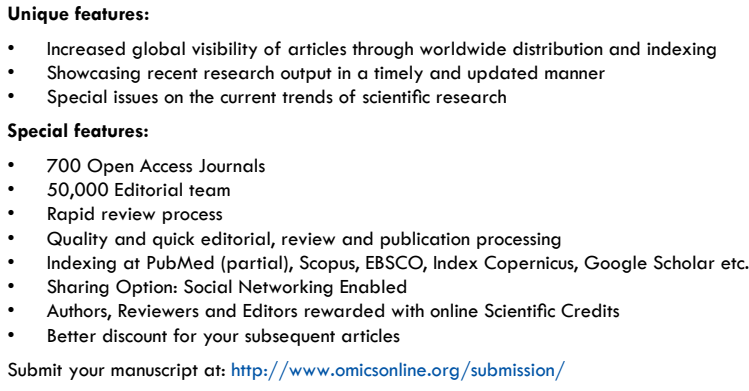

